\title{
Regular Morphology vs. Prosodic Morphology? The Case of Truncations in German
}

\author{
Richard Wiese \\ Philipps-Universität Marburg
}

\begin{abstract}
This paper is a study of the morphology and phonology of truncations in German (also known as i-Bildungen) within the framework of Optimality Theory. Truncations are shown to constitute a widespread and productive morphological pattern in Modern Standard German. The morphosyntactic properties of these forms are shown to follow from the assumption of a regular binary word-syntactic structure in which the base functions as the head, and a phonologically empty morpheme adds other, non-head, properties. The specific phonological properties can then be derived from the operation of a set of ranked constraints in the sense of Optimality Theory. The analysis implies a strong correspondence between reduplication and truncation as two related aspects of prosodic morphology.*
\end{abstract}

\section{Introduction.}

In German as in many other languages, new words are created by forming complex units out of existing units, where the latter are free or bound morphemes that are concatenated linearly. This is the insight provided by both traditional as well as more recent, theoretically oriented descriptions. For German, the handbook by Fleischer and Barz (1995:7) identifies compounding and explicit (i.e., affixal) derivation as central. In this work as well as in others (see, for example, Kanngießer 1985:143, Olsen 1986, or Eisenberg 1998), complex words are described by various types of word-syntactic structures. Word formation which does not rely

\footnotetext{
A first version of this paper was presented in March 1996; the handout from this presentation (Wiese 1996) has been discussed occasionally since. Members of the research project Prosodische Morphologie (part of SFB 282 "Theorie des Lexikons") at the universities of Düsseldorf and Cologne, in particular Chris Golston, Martin Neef, Renate Raffelsiefen, Heinz Vater, Markus Walther, and Anja Werner, have contributed to the early stages of the paper in different ways. In addition, I thank Susanne Niedeggen-Bartke, Caroline Féry, and Birgit Alber for helpful input, and two anonymous JGL reviewers for important criticism and clarifications.
} 
on the chaining of morphemes (concatenative morphology) is generally regarded as peripheral or even odd in descriptive work on German.

In this paper, I attempt to bring one major type of a seemingly nonconcatenative morphological phenomenon of German back under the umbrella of ordinary, concatenative morphology. That is, I will argue that truncations in German, a particular unlikely type of concatenative morphology, are very regular as far as their morphology is concerned. At the same time, relevant prosodic and other phonological aspects of truncations are analyzed, and I provide a new, optimality-theoretic description of German truncations, one that avoids (unnecessary, at least for the present) complications in OT.

The type of word formation I analyze from this perspective falls under the general heading of PROSODIC MORPHOLOGY. Truncations in German are prosodically conditioned, but they are, as this paper will argue, neither marginal nor do they fall outside the scope of regular (concatenative) morphology. In a similar vein, reduplications and socalled template-based word formations are usually taken as standard examples of prosodic morphology. Following a line of research initiated by Benua (1995), I will demonstrate that truncations in German behave in exactly the same way and are most naturally accounted for by using the same tools of analysis that are successfully applied to the former phenomena. These tools are those of OPTIMALITY THEORY, a theory relying on the interaction of violable and universal grammatical constraints.

The empirical domain of this study is provided by the so-called $\mathrm{i}$-Bildungen ( $i$-formations) of present-day German, words that end in /i/, and can be included under the label of TRUNCATION, as they normally relate to a longer, full form. The phenomenon is more precisely delineated in section 2. Two more specific claims will emerge during the course of this paper. First, the proper treatment of these truncations requires reference to both the words from which they are "derived" and to the surface structure of the resulting forms. Second, the truncations are closely related to reduplications as another instance of the prosodic formation of words. A general conclusion will then be that the standard view of concatenative morphology is not called into question by truncations, but is confirmed in a rather surprising way. Such a result is

\footnotetext{
${ }^{1}$ Generally speaking, studies of truncations in Optimality Theory have assumed, more or less explicitly, that truncation is a phenomenon of concatenative morphology, while studies from a different theoretical background have taken
} 
only possible in a theory relying on violable constraints, constraints that are furthermore able to regulate the relationship between various levels of description.

The type of words to be studied here has recently (and in clear contrast to its former marginalization) been the subject of a number of studies, for reasons that will become clear below. The literature on the subject (for German alone!) includes Neef 1996, Werner 1996, Wiese 1996, Féry 1997, Itô and Mester 1997, and Walther 1999. The present paper adds to this list by arguing that the past proposals are not adequate in some respects, empirically and/or theoretically, and by commenting on the differences between the proposals below.

\section{Data and Classifications.}

The $i$-formations alluded to above are traditionally treated as Kurzwörter, 'clippings', literally: 'short words', (see Bellmann 1980, Fleischer and Barz 1995). In the following, I use the term TRUNCATION. A lexical entry belongs to this class if it stands in a clear relation of semantic similarity or even identity to another lexical entry (the base), and if it displays a phonological form that is reduced in comparison to this base. This definition holds both for the truncations in $1 \mathrm{a}, \mathrm{b}$ and those in $2 \mathrm{a}, \mathrm{b} .^{2}$

(1) $i$-formations in German

a. hypocoristic names

$\begin{array}{ll}\text { Rudolf } & \text { Rudi } \\ \text { Andreas } & \text { Andi } \\ \text { Littbarski } & \text { Litti } \\ \text { Gorbatschow } & \text { Gorbi } \\ \text { Oma } & \text { Omi }\end{array}$

the term "truncation" literally and set aside truncation from concatenative morphology.

${ }^{2}$ Here and in the following I present data by arranging the full forms (bases), their truncations, and glosses, where appropriate, in three respective columns. 
b. other formations

Spontaner Sponti 'member of a spontaneous faction of a party'

Professioneller Profi 'professional'

Sozialist Sozi 'member of a left-wing party'

Ostdeutscher Ossi 'East German'

Chauvinist Chauvi 'chauvinist'

(2) Other clippings

a. clippings I

$\begin{array}{lll}\text { Abitur } & \text { Abi } & \text { 'high school diploma' } \\ \text { Universität } & \text { Uni } & \text { 'university' } \\ \text { Kriminalroman } & \text { Krimi } & \text { 'crime novel' } \\ \text { Sanitäter } & \text { Sani } & \text { 'medical assistant' }\end{array}$

b. clippings II

Fotographie

Transformator

\section{Foto}

Trafo

United Nations Organization

Personenkraftwagen

\section{UNO}

Pkw 'photograph'

'transformer'

'automobile'

1a gives examples of $i$-formations used as hypocoristics, $1 \mathrm{~b}$ lists other types for which a hypocoristic use is not as obvious. Words of this kind are the subject of this study. 2a gives examples of clippings that, in the literature on German morphology, are not subsumed under the heading of $\mathrm{i}$-Bildungen because the final /i/ is already part of the base word; see Fleischer and Barz 1995. In 2b, other types of clippings are exemplified that are quite diverse. Examples in $2 \mathrm{a}$ and Foto from $2 \mathrm{~b}$ illustrate a type of clippings called "unisegmentale Kurzwörter" by Bellmann (1980), in which a contiguous chunk of segments from the base is realized. The handbook by Fleischer and Barz (1995:152) treats clippings as fundamentally different from $i$-formations, on the grounds that in clippings no new words are created, while $i$-formations, according to their view, are derived words, because they display "reduction and derivation at the same time" (Fleischer and Barz 1995:222), a view adopted from Bellmann 1980 and Greule 1983. In other words, final /i/ is a suffix in 1, but not in 2a. On the other hand, Féry (1997:467) points out that the types of simplifications found for the two cases are identical. This is important evidence for treating them in a unified way.

For the purposes of this study, the question whether all truncations may be analyzed uniformly can be left open. The view that clippings of type $2 \mathrm{a}$ need to be distinguished from $i$-formations is problematic 
because of their virtual identity in form. But since $i$-formations in the sense of the examples in 1 are, as we shall see, by themselves a large and productive group, the question may remain open. However, it is argued in section 3 that final /i/ in $i$-formations, although perhaps a suffix, does not constitute the head of their respective words. From this perspective, the difference between $i$-formations and clippings such as those in $2 \mathrm{a}$ may be negligible. In the following, I use the term "truncation" to refer to the pattern exemplified in 1 and $2 \mathrm{a}$. The pattern exemplified by Trafo and Foto in $2 \mathrm{~b}$ does not appear to be productive.

Both traditional and generative word-syntactic treatments of German word formation treat truncations as marginal, since their formal structure seems to be radically different from "regular" affix-derived words. However, intuitive preconceptions and theoretical considerations aside, in the semantic domain of hypocoristics such words have always been productive, and in a recent period the pattern has been extended to a large number of nouns such as Compi, Germi, or Phoni, ${ }^{3}$ see the lists of examples below. Therefore, the question is how a language that seems to use affixes as the standard marker of derived words can accommodate a type of word formation in which reduction of bases is dominant. Furthermore, how can such a type of word formation become productive over time, assuming that morphological change prefers the more natural patterns? The answer proposed in this paper is that the reduction is the result of independently motivated phonological wellformedness conditions, while the morphology of truncations is quite regular and not at all different from the rest of the (concatenative) morphology of German.

\section{Possible Forms, Analyses, and Levels of Representation.}

Before addressing the morphological structure of truncations, some properties of their phonological form must be discussed. At the same time, further examples and recent analyses are presented, demonstrating the range of the phenomenon in present-day German and the alternatives in analyzing them. Consider first the list of hypocoristics, a complete list of those proper names in the corpus of Werner 1996 in which the base word contains more than a single intervocalic consonant. ${ }^{4}$ The list in $3 \mathrm{a}$

3 Phoni is hypocoristic for Phonologe 'phonologist', a formation English speakers are particularly fond of. Germi is a truncation of Germanistikstudent 'student of German'.

${ }^{4}$ The list is complete only with respect to Werner's corpus; because of the productivity of truncations it cannot be complete in an absolute sense. However, 
differs from that in $3 \mathrm{~b}$ in that in the former at least one medial consonant found in the base is missing in the truncated form.

(3) Hypocoristic proper names

a. truncations displaying consonant loss

$\begin{array}{llll}\text { Agnes } & \text { Agi } & \text { Henrike } & \text { Henni } \\ \text { Andreas } & \text { Andi } & \text { Herdnia } & \text { Herdi } \\ \text { Benjamin } & \text { Benni } & \text { Irmgard } & \text { Irmi } \\ \text { Brunhild } & \text { Bruni } & \text { Oswald } & \text { Ossi } \\ \text { Konrad } & \text { Conni } & \text { Sandra } & \text { Sandy } \\ \text { Dagmar } & \text { Daggi } & \text { Siegfried } & \text { Siggi } \\ \text { Edmund } & \text { Edi } & \text { Sonja } & \text { Sonny } \\ \text { Gertrud } & \text { Gerti } & \text { Ulrich, Ulrike } & \text { Uli } \\ \text { Elfriede } & \text { Elfi } & \text { Wilhelm } & \text { Willi }\end{array}$

Hedwig Hedi, Hetti

b. truncations without consonant loss

$\begin{array}{llll}\text { Bastian } & \text { Basti } & \text { Mark } & \text { Marki } \\ \text { Cornelia } & \text { Corny } & \text { Maximiliane } & \text { Maxi } \\ \text { Elmar } & \text { Elmi } & \text { Nastasja } & \text { Nasti } \\ \text { Ferdinand } & \text { Ferdi } & \text { (Leo)pold } & \text { Poldi } \\ \text { Frank } & \text { Franki } & \text { Sylvia } & \text { Sylvie } \\ \text { Franziska } & \text { Franzi } & \text { Waldemar } & \text { Waldi }\end{array}$

Comparing the two lists allows for a preliminary statement on the relationship between base words and truncations: complex internal consonant clusters remain intact if they can (!) form the coda of a single syllable. If this is not the case, the cluster is simplified by dropping a consonant. For example, the first syllable from the material provided by the base Andreas could maximally be /and/, or, better because of Final Devoicing, /ant/, but not */andr/..$^{5}$ Therefore, simplification occurs. The first syllable of the base Waldemar, in contrast, is /valt/, without any need for a "deletion" of medial consonants. But note first that the potential form Andri is phonotactically well-formed in German, as exemplified by the very form of the base Andreas, and, second, that the regularity apparent here is not one that can be formulated by referring to the surface syllabification of the words in question: neither in Waldemar

since the list is not biased for present purposes, it may be considered representative.

${ }^{5}$ I will return shortly to the issue of Final Devoicing in the truncations. 
nor in Waldi can we find a single syllable /valt/ or /vald/. Of course, the final consonant is syllabified with following / $\mathrm{i} /$, leading to the truncation forms [?an.di], [val.di].

The first apparent generalization, noted in all other recent studies of German truncations and by Kenstowicz (1994:7) for English, thus seems to be: the material taken from the base is restricted to the first maximal potential syllable. Below, I argue that the generalization is not really correct, or rather, necessitates a problematic recourse to a non-existing syllabification.

Before turning to other aspects of German truncation, it must be noted that the reduction of consonants often goes beyond the degree of reduction just formulated, as demonstrated by the cases in 4 (again taken from Werner 1996). The first maximal syllable of Birgit would be /birg/; nevertheless, a consonant is dropped. In many of these cases, however, double forms exist in Werner's corpus, as the examples in 4 illustrate. Many further examples of this sort exist.

(4) Truncations with further reduction of medial consonant clusters

\begin{tabular}{|c|c|c|c|c|}
\hline Birgit & \multicolumn{2}{|l|}{ Biggie } & Margarethe & Maggie \\
\hline Christiane & Chriss & & (Ma)thilde & Tilli \\
\hline Cornelia & Conni & (Corni) & Olga & Olli \\
\hline Elfriede & Effi & (Elfi) & Oskar & Ossi \\
\hline Franziska & Cissi & & Victoria & Vicki \\
\hline Franziska & Fanni & (Franzi) & Wolfgang & Wolli \\
\hline Manfred & Manni & & & \\
\hline
\end{tabular}

There does not seem to be a satisfactory answer to the question when such additional consonant deletions occur. They are not restricted to hypocoristic names, as witnessed by Ossi and Wessi, which would be *Osti and $*$ Westi if deletions were regulated by the Maximal First Syllable principle alone. I assume that further deletions, as those in 4, are lexicalizations of truncation forms, that is, irregular and unpredictable formations. That Ossi or Wessi could indeed be Osti or Westi is witnessed by the existing form Geisti, for Geisteswissenschaftler 'humanist'. Possibly the structures derived by these further reductions are even less marked than the "regular" truncations.

Neef (1996:282) suggests that these truncations occur in a different, more colloquial register of German. At present, it is doubtful whether there is any evidence for this proposal. There is also no clear answer to the question which consonant from a cluster is to be left out. Neither the position nor the quality of the consonants appears to determine uniquely 
the candidate to be deleted, although it is obvious that the majority of deletions are at the right edge of the cluster. Again, for forms such as Effi (alongside Elli), lexicalization might be at work.

Two further generalizations can be drawn on the basis of 3 and 4 . First, truncations are bisyllabic, with initial stress. Second, they retain the initial segments of the base word in an uninterrupted sequence up to the cutoff point. The first observation is exceptionless for the data in 3 and 4 , though the second is not always true; compare Cissi and Fanni from Franziska. Here, stress patterns might play a role (Franzíska), although it is again not generally the case that the stressed syllable must be kept in a truncation form.

These three regularities are not restricted to the hypocoristic first names, as further data demonstrate. New formations on the basis of surnames (of sports stars and other celebrities) follow the same pattern with respect to consonant clusters, syllabic and stress patterns, and reference to the initial substring; see examples in 5. Gobbi or Klinni do not occur, but would be possible formations (and are therefore marked by a "Vل").

(5) Surnames

a. consonant deletion

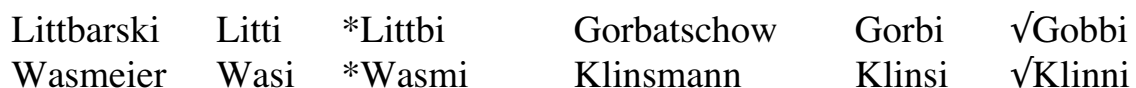

To emphasize the systematic nature of the consonant reduction in truncations, minimal pairs are presented in 6 . The clusters in 6a need to be simplified (and always are), while the mirror image clusters in $6 \mathrm{~b}$ are retained. ${ }^{6}$

(6) Minimal pairs

\begin{tabular}{llll} 
a. consonant & reduction & \multicolumn{2}{l}{ b. no consonant reduction } \\
Gabriele & Gabi & Gorbatschow & Gorbi \\
Heinrich & Heini & Arnold & Arni \\
Hamlet & Hammi & Helmut & Helmi
\end{tabular}

The results so far are summarized in 7 . These statements, first made by Werner (1996), do not by themselves constitute the analysis, but provide only a starting point, and also turn out to be less than absolutely true. An important inference may be drawn however: the generalizations

\footnotetext{
${ }^{6}$ Admittedly, Hammi is an invented form here. All other forms are attested.
} 
are prosodic in nature. The assignment of German truncations to the domain of prosodic morphology is justified by these observations.

(7) General facts regarding truncations

a. They consist of bisyllabic forms.

b. They consist of an uninterrupted string of segments starting from the left of the base word.

c. They consist of a "potential" maximal syllable of the base word plus /i/.

As stated here, the generalizations appear to be idiosyncratic properties of a particular type of word formation in German. Viewed in a wider perspective, however, the generalizations have clear correspondences in the prosodic morphology of other languages. For example, $7 \mathrm{c}$ is also true for English nickname formation (see McCarthy and Prince 1986:60, Kenstowicz 1994:9-10), but is (to the extent that it is a valid generalization; see below) more productive in German. Also, words in many languages may be minimally bisyllabic. Reduplication is often constrained by an equivalent of $7 \mathrm{~b}$, a parallel taken up again later in the paper. The facts summarized in $7 \mathrm{c}$ are actually the apparent result of a number of more elementary conditions to which we will return. This view is part and parcel of optimality-theoretic analyses, as applied to German truncations by Wiese (1996), Féry (1997), and Itô and Mester (1997).

It must be added that all the generalizations have exceptions and are not surface true for all truncations. Some such exceptional forms, as found by Werner (1996), are listed in 8; examples given in 2-4 above provide some more. Truncations may be trisyllabic, they may be based on a string different from the leftmost uninterrupted substring of the base, and they may be based on more than the first maximal syllable of the base. We return to this final observation below, since in the existing literature the limitation to (at most) a maximal syllable is regarded as a characteristic property of $i$-formations (at best allowing for lexical exceptions). 
(8) Exceptional cases

a. Eleganter, Kompostierter, Eleganti, Komposti, Asphalti (cf. 7a) Asphaltbewohner

b. Benedix, Wisnewski

Dixi, Neffi

c. Depressiver

Depri (also, Depi)

The example of Depri is resolved by reference to its morphological structure in section 5.3 below. A further observation on truncations relates to the much-discussed rule of Final Devoicing in German. ${ }^{7}$ As shown in 9, segments that are realized as voiceless in the base word, but that can be shown to alternate with respect to voice, are voiced in the truncation form. This is a property that is less than obvious, assuming that truncations are formed with reference to the base word. Furthermore, ${ }^{*} \mathrm{Hau}[s] i$, ${ }^{*} \mathrm{Er}[t] i$ and ${ }^{*} \mathrm{Han}[t] i$, although impossible as truncation forms, would be possible word forms in German, and Profi, etc., demonstrating that voiceless obstruents may occur freely in truncations, but only if the obstruent relates to a voiceless non-alternating consonant (as /f/ in Professioneller).

(9) Alternating obstruents

\begin{tabular}{|c|c|c|}
\hline Hausi [havzi] & Hausaufgabe [haus.Paufga:bə] & 'homework' \\
\hline Erdi [?zedi] & Erdkunde [?evt.kundə] & 'geography' \\
\hline Handi [handi] & Handarbeit [hant.?apbart] & 'needlework' \\
\hline Flugi [flu:gi] & Flugblatt [flu:k.blat] & 'flyer' \\
\hline
\end{tabular}

In other words, obstruents in truncations are voiced if they correspond to underlyingly voiced segments. These data, for which no exceptions are known, argue against the view that the regularities for truncations are exclusively based on the surface forms of their base words. This is one of the major problems of current theory, one that addresses relevant levels of representation, to which I now turn.

Generative phonology in the tradition of SPE (Chomsky and Halle 1968) accounts for the structure of complex words by applying a series of morphological and phonological rules to underlying forms. In various strands of more recent research an alternative is pursued: wellformedness conditions are stated, and the interaction of such conditions delivers the

\footnotetext{
${ }^{7}$ On Final Devoicing (Auslautverhärtung) in the recent literature, see Wiese 2000:200-205 and, most thoroughly, Brockhaus 1995. It is usually, though not uncontroversially, interpreted as the devoicing of obstruents in the syllable coda or at the right syllable edge. Its precise status is not relevant here.
} 
structure of a well-formed word. One such approach, Optimality Theory, is exemplified below. In addition, complex words are often described by relating them to the surface structure of other (simple or complex) words. For such research applied to German, see, for example, Alber 1998, Becker 1990, Raffelsiefen 1995, Walther 1995, and Neef 1996. The latter, Neef 1996:278-284, also considers truncations and is discussed below.

Insofar as the observations on the role of a non-surface-true "maximal syllable" and on the absence of Final Devoicing call such an approach into question, I sketch at this point a classical derivational description. It relies on a conception proposed by McCarthy and Prince (1990) for different prosodic-morphological phenomena. According to McCarthy and Prince, the crucial step of an analysis is CIRCUMSCRIPTION, cutting out a relevant part of the base material and making it available for further derivational steps.

Applying this idea to truncations allows for the analysis given in 10 and 11, using the minimal pair of Arnold vs. Heinrich with mirror-image internal consonantal clusters. On the basis of the underlying segment strings $(10 \mathrm{a}, 11 \mathrm{a})$, the initial maximal syllable is computed, which renders the difference between the two forms $(10 \mathrm{~b}, 11 \mathrm{~b})$. (Other segmental and syllabic details are ignored.) Attaching /i/ as the final step gives the two hypocoristic truncation forms.

(10) Derivation of Arni from Arnold

a./arnolt/ underlying

b. $\sigma \quad$ maximal initial syllable (but $\mathrm{cf}$. ar.nold!)

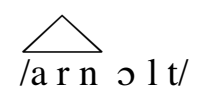

c. /a r n i/ addition of /i/

(11) Derivation of Heini from Heinrich

a./h a I $\mathrm{n}$ r I ç/ underlying

b. $\sigma \quad$ maximal initial syllable (cf. *heinr.ich)

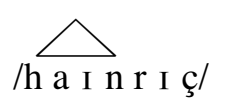

c. /h a $\mathrm{I} n \mathrm{i} / \quad$ addition of $/ \mathrm{i} /$

This analysis is successful in that it derives the correct truncation forms from the base words, but a number of questions arise. The first, quite general, objection that may be raised to this type of circumscriptional analysis is that the delineated substrings are not independently 
motivated prosodic constituents. ${ }^{8}$ Syllable codas are generally minimized and not maximized as suggested in the analysis above. The "potential maximal syllable" is therefore as arbitrary as any other substring from the base material. Second, the analysis remains silent on the status of the final /i/. The steps in 10c and 11c may, without any difference, be interpreted either as the catathesis of a segment $/ \mathrm{i} /$, or as the suffixation of a morpheme. Finally, the specific prosodic structure of the resulting forms, in particular their bisyllabicity, appears to be an arbitrary side effect of the steps taken, namely the circumscription of one syllable plus the addition of a vowel. That the "deletion" of material is found only if a bisyllabic form would not be the result appears as a happy coincidence of the interaction of rules. This is the typical case of a rule conspiracy.

An analysis that seems to be quite different from the derivational one sketched in 10 and 11 is that proposed by Neef (1996:278-284). Neef first discusses a prosodic condition hinted at in Wiese 2000:64 for truncations that says "Build a prototypical foot ending in /i/ from a noun." He points out that the condition specifies a target structure for these nouns, while the theory used by Wiese is one applying rules to underlying forms. This contradiction between desirable generalizations and the theoretical underpinnings is supposed to be resolved, in Neef's work, by a description solely based on output generalizations.

In this theory, called WORD DESIGN, well-formed words result from the interaction of phonological and morphological wellformedness conditions formulated on output structures. Affixes play no role in this model; therefore, truncations do not have one. Phonological wellformedness conditions are general, inviolable conditions, while morphological wellformedness conditions (DESIGN CONDITIONS) hold for words of specific classes and may be violated. The design conditions for truncations are formulated as follows:

\footnotetext{
${ }^{8}$ On the general level, McCarthy and Prince (1993b) have raised this point with respect to their own, earlier proposals. Féry (1997) points out its relevance with respect to German truncations.
} 
(12) Design conditions for the lexeme formation pattern Compi:

i. The stem sequence must end in $/ \mathrm{i} /$.

ii. The design condition Maximal Syllable Rhyme holds with respect to stem-final $/ \mathrm{i} /$.

iii. A word form representing this lexeme formation pattern must be a bisyllabic phonological word.

iv. The base can be shortened.

(Neef 1996:284; my translation, R. W.) ${ }^{9}$

This analysis of truncations is not without empirical and theoretical problems. First, it is unclear in which sense the string of segments including /i/ (Stammsequenz) should be called a stem. Of course, in the word Computer the stem is not $/ \mathrm{komp} /$. The proposal seems to imply that Computer and Compi are made from two completely different stems. ${ }^{10}$ Perhaps this is just a terminological problem. The question as to the status of the maximal syllable rhyme is more serious. As Neef admits in other places, the rhyme here is a potential one, one that is not present in the surface words. But if this is true, then the description is not strictly surface-oriented. In contradiction to the basic claims of the theory, reference is made to abstract, unrealized properties. The description is, in a way not made explicit, procedural and not declarative. The maximal syllable rhyme needs to be computed over the base; the rest of the base is ignored. The parallel to an earlier theory of PROSODIC MORPHOLOGY by McCarthy and Prince $(1986,1990)$ is now obvious. In this theory, such procedural operations ("prosodic circumscription") play a central role, as we saw in 10 and 11. Finally, the status of condition iv in 12 may be questioned. Condition iii already requires a bisyllabic word, which seems to be sufficient. Furthermore, as "shortening" (kürzen) again denotes a

\footnotetext{
9 "Designbedingungen für das Lexembildungsmuster Compi. i. Die Stammsequenz muß mit /i/ enden. ii. Es gilt die Designbedingung des Maximalen Silbenreims bezüglich des stammfinalen/i/. iii. Eine Wortform, die dieses Lexembildungsmuster repräsentiert, muß aus einem zweisilbigen Phonologischen Wort bestehen. iv. Die Basis kann gekürzt werden." (Neef 1996:284)

${ }^{10}$ My proposal below (see 19) indeed uses two stems for the morphological structure of truncations. But these are two compounded stems, one of which is empty (except for the suffix /i/).
} 
procedure and not a static condition, the elimination of this condition is probably desirable on internal grounds. ${ }^{11}$

As a general observation on the proposal we may add that each of the conditions in 12 is understood as being specific for the truncations (Lexembildungsmuster Compi). There is no implication here that they have any status beyond the particular phenomenon under discussion, neither for German nor for any other language. This approach then misses further possible generalizations, such as the possibility that the bisyllabic form of the truncations is only an example of the general preference for binary structures. In the analysis proposed below, the claim is defended that all conditions (except for the requirement of a final $/ \mathrm{i} /$ ) are in fact of a general nature.

There is, actually, evidence that the empirical claim requiring the generalization to make reference to a "potential maximal syllable" is not really correct. For words of specific shapes, it appears that strings of segments occur in truncations that can never appear within a single syllable; see 13 .

(13) Truncations beyond the maximal syllable

\begin{tabular}{|c|c|c|c|}
\hline a. full form & b. truncation & c. max. syllable? & d. gloss \\
\hline Imker & Imki & $*[\ldots \mathrm{Imk}]_{\sigma}$ & 'beekeeper' ${ }^{\prime 2}$ \\
\hline Ingrid & Ingi [?Ingi] & $*[\ldots \text { Ing }]_{\sigma}$ & (fem. name) \\
\hline Pinguin & Pingi [pingi] & $*[\ldots \mathrm{I} y g]_{\sigma}$ & 'penguin'13 \\
\hline Transparent & Transpi & $*[\ldots \mathrm{nsp}]_{\sigma}$ & 'banner' \\
\hline Depressiver & Depri & $*[\ldots \mathrm{pr}]_{\sigma}$ & 'depressive person' \\
\hline
\end{tabular}

What the examples have in common is that the medial clusters are such that they may not appear syllable-finally for various reasons, such as double-place specifications (as for $/ \mathrm{mk} /$ ) or because of a rule of $g$-deletion deleting /g/ after a nasal at the end of a syllable (see Hall 1992a:219-220, Wiese 2000:224-229, and Itô and Mester forthcoming

\footnotetext{
${ }^{11}$ I do not want to address the question whether $12 \mathrm{iv}$ is correct in referring to a bisyllabic phonological word (and not a foot). The foot as a prosodic category has no place in Neef's proposals.

${ }^{12}$ Itô and Mester (1997:8) give Imki, but mark it as ungrammatical and present Immi as the possible truncation form of Imker. From the basis of my own judgment and that of informants, I conclude that Imki is wellformed.

${ }^{13}$ This example I owe to Alan Prince, who reports it for English. It works equally well for German.
} 
for discussion). Whether there is such a rule or not is irrelevant here; in any case, a German syllable cannot end in the cluster [ng]. The final cluster $/ \mathrm{nsp} /$ in Transpi is also excluded by a constraint requiring the third consonant in a syllable-final cluster to be coronal (and not labial as in $/ \mathrm{nsp} /$ ). ${ }^{14}$ Word-internally and across syllables, the relevant clusters are marked, but are nevertheless possible, as both the full forms as well as the truncation forms in 13a demonstrate. Insofar as evidence exists at all, it is clear that the clusters are not reduced in truncations, at least not to the extent predicted by the generalization relying on the "potential maximal syllable."

The issue of the velar nasal is a complex one. There are more personal names of the type Ingrid; compare Ingo, Inga. For all of these, the hypocoristic form is Ingi ([Ingi]). Note that the female name Inge [?Inə] also becomes Ingi [?Ingi] under truncation. (If followed by a full vowel, the cluster [ $\mathrm{ng}$ ] is possible in German, while the same cluster cannot be followed by the vowel schwa.) There is no reason to assume that we are dealing with lexical exceptions here. While abstract solutions involving the deletion of segments are often disputed, the truncation forms of German might provide additional evidence for such an analysis with regard to the distribution of $/ \mathrm{g} /$. Abstract analyses have a long history with respect to /g/ and the velar nasal in German, ranging from Isačenko 1963 to Itô and Mester forthcoming. Whatever the correct analysis is, the fact remains that the cluster [ $\mathrm{ng}$ ] is ruled out syllablefinally, but is found in truncations.

The truncation forms in 9, in which Final Devoicing is bled under truncation, must be added here. There are no syllables in German with a final voiced obstruent (which is the substantive content of the rule of "Final Devoicing"), and in this sense the material appearing before /i/ does not constitute a "potential final syllable."

Thus, the generalization claiming that "maximal potential syllables" are retained in truncations is very questionable. Furthermore, the counterexamples do not appear to be lexicalized exceptions. However, most recent analyses mentioned above presuppose the correctness of the

\footnotetext{
${ }^{14}$ However, the final two examples in 13 should be set apart from the preceding ones. They involve a prefix, and there is evidence that prefix-stem structures are treated differently. I briefly return to these items at the end of section 5.
} 
generalization. ${ }^{15}$ It would of course be possible to add exception clauses to the generalization, for example, by saying that the "potential syllables" are exempt from syllable-final devoicing. But the solution would lose much of its former attraction; the "maximal potential syllables" would no longer be the syllables of German.

An alternative proposal is provided by Walther (1999), who suggests that, instead of a "maximal syllable"-related cutoff point, the sonority minimum provides the crucial condition for truncations. German truncations are computed over segment-inherent sonority values, where the sonority classes are those given in 14; see Hall 1992b, Wiese 2000:260-269.

\section{(14) Sonority scale for German}

obstruents $>$ nasals $>/ 1 />/ \mathrm{r} />$ high vowels $>$ vowels

A series of segments from one sonority class constitutes a sonority plateau. Truncations, according to Walther 1999, make use of all segments up to and including the first sonority minimum. As the set of obstruents is rather large, and as a sequence of them may occur across a syllable boundary, such a minimum may consist of a plateau, that is, the series of segments in this minimum. Walther's proposal avoids any reference to a non-existing potential syllable. It has the additional advantage of being computer-implemented, and as the Internet user can verify, ${ }^{16}$ his model will deliver the truncation Chruschtschi for the full form Chruschtschow, working on the assumption that $/ \mathrm{ft} \mathrm{f} /$ constitutes such an extended sonority minimum. From a computational phonology point of view, the advantage of a sonority-oriented description over a syllable-oriented description is that sonority values of segments are (presumably) constant, while the association of segments to syllables is variable, as in coda-to-onset resyllabification. This is why other descriptions discussed previously need to refer to "potential" syllables. On the other hand, the sonority minimum does not constitute a universally present prosodic constituent. The question remains why this minimum (and not some other value, such as the maximum) should provide the cutoff point.

15 Féry (1997:468-470) questions the use of the "maximal syllable" as a constituent to use in the computation of truncations, but does not doubt its empirical validity.

${ }^{16}$ The system is accessible at the following web address:

http://pc0864.germanistik-kunst.uni-marburg.de/ walther/i-truncations.html. 
On a different level, it is unclear whether the proposal by Walther is empirically correct. The form Chruschtschi is otherwise unattested, and other sonority plateaus seem to be equally absent. Instead, the full form Gymnasium 'high school' (with its sonority plateau and minimum $/ \mathrm{m} . \mathrm{n} /$ ) has the attested truncation form Gymmi, and not *Gymni, where the full sonority minimum is not retained. ${ }^{17}$ For the time being, I assume that a sonority-based framework does not provide a viable alternative. However, as shown in section 5.2 below, sonority differences (between coda consonants and following onsets) are one crucial element governing the elimination of consonants.

The most obvious point of comparison to the proposal developed below is provided by optimality-theoretic analyses of German truncations, in particular those by Féry (1997) and Itô and Mester (1997). The analysis developed in section 5 is inspired by these and shares some fundamental assumptions, but departs in some ways from both. Féry (1997) uses a number of constraints that express prosodic wellformedness and demand identity between inputs and outputs. But most of the relevant constraints need to be restricted to the domain of truncations, in order to ensure that truncation forms are different from other word forms. The need for such truncation-specific constraints derives from the fact that her analysis does not include a particular morphological structure for truncations, as the present paper does in the following sections. The lack of such a specific structure must be compensated by truncation-specific versions of constraints.

Itô and Mester (1997) base their analysis on a different variant of Optimality Theory called SYMPATHY THEORY, and argue that in fact German truncations provide evidence for this conception. ${ }^{18}$ They start from the claim (illustrated above) that the input to some of the truncations is a "possible syllable" (1997:8), a syllable neither in the input nor in the output of German truncations. Such syllables play an indirect role in the selection of the optimal candidate, as they are part of the socalled "sympathy candidate," the candidate that best satisfies a constraint placed at the top of the constraint hierarchy for this particular purpose

\footnotetext{
${ }^{17}$ The proposal would also predict the wrong form * Littbi for Littbarski (see 5a). Walther suggests that the full name is a pseudo-compound, but this is unlikely to be true: while simple compounds bear stress on the left, Littbárski has stress on the right.
}

${ }^{18}$ The theory is proposed and described in detail by McCarthy (1999). 
(although it is otherwise ranked lower). The constraint in question is one demanding that all syllables appear at the left of their prosodic word, in effect leading to a monosyllabic form. Working together with constraints demanding minimization of truncation, the analysis succeeds in deriving Andi from Andreas, but does not admit *Andri or *Ani, since [and] is the "possible syllable" selected as the sympathy candidate (which is also suffixed by /i/). On a general level, Sympathy Theory is designed to deal with cases of "opacity," generalizations assumed in phonology that are not surface-true and therefore not part of the output (the usual domain to be evaluated by constraints). The sympathy candidate provides a means of acknowledging such non-surfacing information (such as the "potential maximal syllable" assumed to be relevant for German truncations) and making systematic reference to it.

However, there are serious empirical problems surrounding this "potential maximal syllable," as discussed above. ${ }^{19}$ In addition, there is a fundamental theoretical problem here. As further discussion of Sympathy Theory, most prominently by Itô and Mester (forthcoming), has pointed out, the approach involves a serious expansion of the framework, undesirable for reasons of economy. Furthermore and more importantly, Sympathy Theory seems also unable to account for other cases of opacity, even though it allows for (and requires) considerable reranking of constraints within a grammar (an option not foreseen by the basic axioms of Optimality Theory). This can be illustrated by the German truncations once again: the analysis by Itô and Mester (1997) proposes to make the constraint "All syllables left" the dominant one in order to select the sympathy candidate. But the same constraint must be downscaled for other areas of German phonology (given that it is not generally true that all inputs are reduced to a monosyllabic form).

\section{The Morphology of Truncations.}

Next, some necessary assumptions on the morphology of truncations are discussed. There are two basic, but related, problems here. The first is the status of final $/ \mathrm{i} /$, the second is the wider context in which truncation as a morphological phenomenon should be placed. I address each of these problems.

${ }^{19}$ Itô and Mester (1997:14-16) discuss the non-application of Final Devoicing in this respect; see 9 in the present paper, but, as argued above, there are additional ways in which the "potential maximal syllable" is not a syllable of German. 


\subsection{The Status of Final /i/.}

As mentioned earlier, handbooks on German morphology treat truncation as a marginal phenomenon, and then concentrate on the question whether final /i/ is a derivational suffix or not. Fleischer and Barz (1995:222), in particular, decide to interpret /i/ as a suffix if it is not part of the base, cf. $1-2 \mathrm{a}$. This type of truncation is thus characterized by the suffix /i/ plus a reduction in material, while there is no such suffix in, for example, Uni from the full form Universität 'university'.

This morphemic view is problematic since the supposed suffix does not display the properties otherwise associated with a derivational suffix: neither does the suffix determine the gender of the form, nor does it determine other grammatical features, such as those of word class or those marking the distinction between common nouns and proper nouns. Rather, all of these features are those of the base word. Note that derivational suffixes in German generally do determine grammatical gender (for nominal features), word class, or other features (such as abstractness, noun status, etc.), and that most of them involve a change of word class. Examples in 15 demonstrate the inability of /i/ to change the gender of nouns. The gender is always that of the base word. Furthermore, gender-variable truncations are possible if and only if they exist in the base form, see 15a,b. As truncation forms are generally nouns referring to persons, examples in the neuter are rare. However, forms such as das Kindi (< Kind, 'child (neut.)') or das Radi (<Rad 'wheel (neut.)') are possible, see also Werner 1996:26-29 for examples. Any gender preferences for truncations seem to be solely based on the fact that animate objects are more easily subject to hypocoristic morphology, and that they also, more often than not, correspond to words bearing nonneuter gender.

(15) Gender-variable truncations

a. masculine

der Bhagwan-Anhänger

'the Bhagwan follower (masc.)'

der Soldat in Grundausbildung

'the soldier (masc.) in basic training'

der Bhaggi

der Grundi

b. feminine

die Bhagwan-Anhängerin

'the Bhagwan follower (fem.)'

die Grundausbildung

'the basic training (fem.)'

die Bhaggi

die Grundi 
Derivational suffixes prototypically have the function of changing (or at least determining) the word class of the resulting word. Neef (1996:278) and Werner $(1996: 3,28)$ argue that truncations are possible on the basis of words of all classes; in that sense, truncations would involve class-changing morphology. However, there does not seem to be a good reason for the claim that Dummi, for example, is formed on the basis of adjectival dumm 'stupid', and not Dummer 'stupid person' or Dummchen 'stupid person (dim.)'. Uncontroversially, the great majority of truncations is based on nouns, in any case. Therefore, there is no reason to give truncations the power to change word class identity if the only evidence is from examples that are ambiguous with respect to word class. Furthermore, there is at least one attested example of a truncation form that is clearly not a noun: supi (from super) functions as a intensifier just as the base form does. In other words, if final $-i$ is a nounforming suffix in the majority of truncations, it is necessary to claim that final $-i$ in Dummi is a different suffix (with identical prosodic morphology), and that it is yet another suffix in supi, (with identical prosodic morphology once again). Furthermore, the diminutive or hypocoristic meaning (in the sense to be discussed below) is present in all of these cases. At best, the suffix /i/ is the carrier of this semantic part of the formation, but it is not responsible for the grammatical properties of the word.

There is one systematic exception to the claim that truncations are morphosyntactically identical to their base words: all truncation forms seem to be members of a single inflectional class, namely that in which the plural marker is $-s .16$ gives a few examples. Since derivational noun suffixes of German generally determine their plural marker, it seems to follow that /i/ is such a suffix.

(16) Plural forms of truncations

$\begin{array}{lllll}\text { full form } & \text { plural } & \text { truncation } & \text { plural } & \\ \text { Flugblatt } & \text { Flugblätter } & \text { Flugi } & \text { Flugis } & \text { 'flyer' } \\ \text { Student } & \text { Studenten } & \text { Studi } & \text { Studis } & \text { 'student' } \\ \text { Computer } & \text { Computer } & \text { Compi } & \text { Compis } & \text { 'computer' }\end{array}$

The first problem with this argument is that all other short forms, abbreviations, or clippings in German (see 2 for examples of the major types) share this property with the truncations proper. If these former words do not bear a suffix and still take plural $-s$, it follows that a hypothetical suffix $-i$ alone cannot be responsible for the pluralization with $-s$. In addition, nouns ending in a full vowel without primary stress 
are also generally subject to pluralization with the suffix $-s$. There is therefore no reason to regard truncations as a morphosyntactic class of their own with respect to plural markers. Below, in section 5, the truncations and their plural forms are put in yet a wider context, one that includes reduplications. The particular plural form then finds a different explanation. In any case, there seems no reason to assume that a suffix /i/ is responsible for the plural suffix /s/.

As for the distinction between common nouns and proper nouns, it is again the case that truncations do not cause any change here: a common noun is still a common noun under truncation (Student, Studi), and a proper noun is still a proper noun (Hans, Hansi).

\subsection{Truncations as Reduplications.}

More evidence on the role of /i/ will come to light once further aspects of the morphology and semantics of truncation forms are studied. The formal proposal to be made below relies on the claim that truncations are closely related to another phenomenon of prosodic morphology, that of reduplication. This is the topic addressed next.

Reduplication is a widespread phenomenon in the languages of the world (see Moravcsik 1978 for a survey), though it is rather marginal in German and in related languages. The latter fact is the result of a continuous decline of reduplication from Proto-Indo-European to New High German. Sanskrit, Classical Greek, and, more sparsely, Latin, display forms of reduplication as integral parts of their respective morphological systems. In New High German, reduplication has no systematic morphological function.

In 17, some reduplicative patterns are illustrated. 17a exemplifies syllable reduplication in Ilokano, $17 \mathrm{~b}$ a (near-)complete reduplication in Balangao. Here, the non-reduplication of the stem-final $/ \mathrm{g} /$ or $/ \mathrm{n} /$ in the simplified forms of $17 \mathrm{~b}$ follows, according to the analysis by McCarthy and Prince (1994, 1995), from the preference for open syllables, while the higher constraint demanding faithfulness between input stem and base leads to the retention of stem-final segments. The preference for open syllables can only be made visible at the end of the reduplicative prefix; in the stem and medially in the prefix, syllable-final $/ \mathrm{g} / \mathrm{must}$ be kept in order to fulfill other, higher-ranking constraints. The analysis of truncations in section 5 will demonstrate how such preferences and conflicts between them can be put to work in the description of such words. Classical Greek (17c) uses a minimal reduplicative prefix (one consonant from the base and a fixed vowel /e/) to mark the perfective 
participle. It is exactly such a systematic use of reduplication that is not found in present-day German, while fixed vocalism is part and parcel of German truncation.

(17) Reduplication patterns

a. Syllable reduplication in Ilokano

$\begin{array}{lll}\text { kaldín } & \text { kal-kaldín } & \text { 'goat(s)' } \\ \text { púsa } & \text { pus-púsa } & \text { 'cat(s)' } \\ \text { kláse } & \text { klas-kláse } & \text { 'class(es)' }\end{array}$

b. Near-maximal reduplication in Balangao

tagta-tagtag 'run everywhere'

tayna-taynan 'repeatedly be left behind'

c. Minimal reduplication in Classical Greek

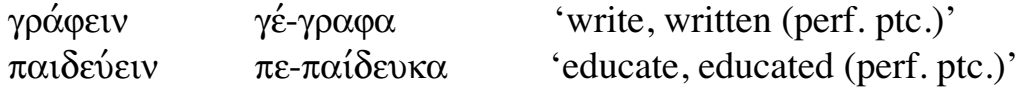

New High German still uses reduplicative forms, but to a very limited extent. On the basis of the extensive collection provided by Bzdega (1965), Wiese (1990) counts reduplicative forms. According to this list, at most ninety reduplicative forms can be regarded as generally known in present-day German. In 18, a sample of these forms is given. 18a displays forms that show an alternation either in the vowel (ablauting) or in the initial consonant, but that are otherwise complete reduplications. $18 \mathrm{~b}$ contains forms in which a medial, and also final, /i/ occurs, a segment that is not present in the base morpheme.

(18) Reduplication in German

a. Zickzack, Pingpong, Krimskrams, ruckzuck, Hokuspokus

b. Schickimicki, Ruckizucki, holterdipolter, wischiwaschi

The relation between reduplications and truncations in German is already apparent, though it is still quite superficial: both phenomena belong to the domain of prosodic morphology, and words of both types display an /i/ that does not have a clear morphemic status as a derivational head. But the relation can be shown to be more specific and direct. In the following, I argue for the claim that truncations are basically reduplicative constructions but those in which prosodic wellformedness conditions prevent the double realization of the material. The following arguments from phonology, morphology, semantics, and/or usage speak for the claim that truncation and reduplication are two variants of one and the same phenomenon. 
1. Reduplications in German can, as shown in 18, double prosodic constituents such as rhymes or syllables. Truncations are equally constrained by prosodic constituents. More generally, they are two subtypes of prosodic morphology, in German and elsewhere.

2. Reduplications may contain, just as truncations, prespecified material, i.e., phonological material that is not taken from the base and that is, at the same time, not a derivational suffix for the overall word. This characterization holds both for /i/ in truncations and for /i/ in reduplications, see $18 \mathrm{~b}$. That is, the prespecified material is actually identical in the two cases. This material does not appear in all reduplications, but given the unproductive nature of German reduplication, this is not surprising.

3. Some reduplications in German are interjections and often onomatopoeic, see piff-paff or holterdipolter. The large majority of others are nouns, just as truncations. In other words, the two constructions share an identical range of possibilities with respect to word class. Verbs seem to be excluded altogether from both groups.

4. There is a similarity in meaning and/or usage which can hardly be coincidental. Both constructions have "emotional closeness" in a wider sense at their semantic core; both are found in various nonstandard varieties of German rather than in the standard, written language. Both types of formations are also particularly common in children's speech and in motherese (caretakers' speech).

5. Truncations take the plural marker $-s$, see 16. Insofar as reduplications allow pluralization at all, they show the same plural marker, e.g., Schickimickis, Zickzacks. Given the rarity of plural $-s$ for morphologically defined classes in the German noun system, this could hardly be a coincidence.

6. Finally, it is the case that truncation is productive in New High German, while reduplication is not. The number of lexical, noninterjectional reduplications is, as noted, quite small. In this respect, there is a near-complementary distribution between truncation and reduplication in German morphology: one is widespread and productive, while the other is restricted to a few lexicalized forms.

The obvious similarities (points 1 through 5), together with the complementary distribution in the morphological system (point 6), allow 
for the conclusion that truncations appear exactly where reduplications do not. They are really one and the same thing: characters comparable to Dr. Jekyll and Mr. Hyde. Furthermore, given that there is a range of reduplicative patterns from full reduplication (17b) down to minimal reduplication $(17 \mathrm{c})$, it is reasonable to assume that truncation is the other endpoint of the scale: no reduplication with otherwise identical input of morphemes.

In some of the early analyses of prosodic morphology (e.g., Marantz 1982, McCarthy and Prince 1986), reduplication is analyzed as follows: a prosodic constituent (typically a syllable, mora, or foot) is attached as an affix. This segmentally empty affix is then filled, so to speak, with a copy of the base material. More recent analyses of reduplication within Optimality Theory do not make use of such empty prosodic nodes, but likewise stress the prosodic nature of reduplication and assume a phonologically empty, but otherwise regular, morpheme that leads to reduplication. However, the tendency toward the use of prosodically unmarked constituents is brought to light more clearly in these analyses.

After having established the close relationship between truncation and reduplication, the discussion on the status of the final /i/ (in both constructions) can now be taken up again. The following observations argue against the view that /i/ is the derivational head of the word:

1. It does not show any of the crucial properties of a derivational suffix; for details see the discussion in section 3.1. In other words, in no respect is $-i$ the grammatical head of the word it is a part of. As for gender assignment, /i/ differs in this respect from the diminutive suffixes -chen and -lein, which always assign neuter gender.

2. Final /i/ could not be regarded as an inflectional suffix either, since these refer, in German, to a clearly delimited set of categories; for nouns, this set comprises gender, case, and number.

3. The possible meaning assigned to /i/ would be "hypocoristic" (Verniedlichung) in the widest sense. Hypocoristics can indeed have a grammatical status in languages, but the case of German truncations is less clear. It is even unclear whether one should refer to a semantic aspect of truncations in a strict sense. Bellmann (1980) emphasizes that the distinction between full forms and truncated forms is not of a semantic, but of a pragmatic-discursive nature, a view that is shared by Féry (1997). Nevertheless, I interpret /i/ as a suffix with a hypocoristic meaning. 
4. Medial or final /i/ in reduplications (see 17b) has a status comparable to that of /i/ in truncations. For the former /i/, a morphemic analysis has never been considered, to my knowledge, but if it is a morpheme, then it is not the head of the overall word, because it is not obligatory for reduplications, and because reduplications belong to different word classes (nouns, adverbs, and adjectives, perhaps).

5. The final /i/ does, however, carry a prosodic function: it provides the forms with a second (unstressed) syllable, which, in addition, is open. Given that there are good reasons to claim that the preferred word in German carries word stress on the penultimate syllable (Wiese 2000:272-311, Féry 1998b), we observe that this is precisely what is found for truncations. In this respect, final / $\mathrm{i} /$ serves a similar function as final schwa (as in Blume 'flower', Riese 'giant', etc.).

6. As noted above, truncations mark a plural form by the suffix $-s$. The wider context of this regularity obviously is not that of a suffix $-i$ determining its plural form, but that of prosodic word formation, of which reduplication, truncation, and abbreviations (e.g., $L K W s$ ) are specific instances. The $s$-plural can be interpreted, following Marcus et al. 1995, Wiese 2000, and other authors, as an emergency or default plural marker in German. While common nouns normally belong to a lexically (morphologically and/or phonologically) defined noun class and then take either -er, -e, -en, or zero as a plural marker, nouns that are not part of this lexical core take $-s$. Among these nouns are proper nouns, recent borrowings, conversions (seine Wenns und Abers, 'his ifs and buts'), and also the results of prosodic morphology discussed in the present paper. Marcus et al. (1995) present judgment experiments with adults as evidence for the claim that $-s$ constitutes a default affix despite its low frequency among common nouns. There is numerous additional evidence for this claim, in particular from studies on normal and impaired language acquisition (most recently Bartke 1998) and on processing and brain activity (Weyerts et al. 1997). This work is summarized by Clahsen (1999) and Pinker (1999:211-239). The fact that all nouns resulting from prosodic morphology of various types use the default plural suffix $-s$ (including suitable reduplicative forms!) has not been given proper attention.

I emphasize again that all types of words derived by shortening are suffixed with the plural suffix $-s$. The identity of reduplicative and truncatory words is demonstrated here as well. In a model separating 
lexical from postlexical morphology the $s$-plural could possibly be assigned to the postlexical component. In descriptions based on the theory of Lexical Phonology, this plural is often assigned to the final level of the lexicon (Wiese 1986 and 2000:115-149), thereby expressing the default characteristics of this plural.

If final /i/ does not form the morphosyntactic head of the respective word (truncation or reduplication), then it may still be a suffix (although it could also be pure phonological material, a so-called augment), but there must be some other morpheme that serves as the head of the construction. Since schwa is clearly the vowel of epenthesis in German, it is unlikely that $/ \mathrm{i} / \mathrm{is}$ added as a default vowel without any morphological function.

In other words, questions of morphological structure must be addressed seriously at this point. Recall the widespread assumption that truncations (in German) are somehow deviant and not in accordance with run-of-the-mill concatenative morphology. In the following, this assumption is rejected. Instead, the hypothesis is put forward that, morphologically, truncations are completely normal and unmarked.

In order to substantiate this claim it is necessary to make some degree of commitment to morphological structure. Following a large number of studies on the syntax of words (e.g., Selkirk 1982, Höhle 1982, di Sciullo and Williams 1987, Olsen 1986), I assume some version of a grammatical word structure component involving morphological categories (such as root, stem, word, affix) plus a restrictive phrase structure rule system. Crucially, I endorse a notion of morphological head within such structures. The head (situated at the right edge of wordlevel constructions in Germanic languages) determines the morphosyntactic features of a construction.

Two crucial assumptions determining the structure of truncations have now been made: if truncations have a regular morphological structure and if they are virtually identical to reduplications, their morphological structure should be that given in 19, exemplified by the name Andreas. A reduplicative affix (more precisely, a phonologically empty prefix, often abbreviated as RED) precedes the suffix /i/, which in turn precedes a stem containing the base word (Andreas in the present example). ${ }^{20}$ The terminal nodes specify the phonological content of the three morphemes.

${ }^{20}$ The proposal is heavily inspired by the analysis of English table-shmable given by Alderete et al. (1999). In their analysis, words of this sort consist of 
(19) Morphological structure of German truncations

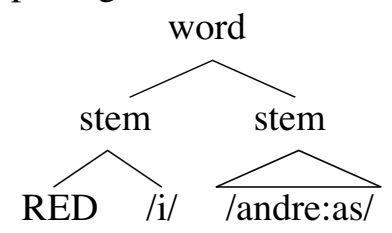

This construction is a regular, binary word-syntactic structure, just like that of most or all complex words. Nothing hinges on the categories "word" and "stem" in 19, and it is possible that the left-hand stem, comprising RED and /i/, is in fact a complex prefix. Crucially, however, the base stem is in the rightmost position and can therefore act as the morphological head, in order to determine the grammatical features of the higher category, the word, as the facts dictate. The morpheme RED is completely regular, with the exception that it has no phonological content, because there is no segmental or other content that is constant over the truncations.

Writing "RED" is potentially misleading here; the morpheme in question is a phonologically empty morpheme, called RED to signify its historical origin in studies of reduplication, and its identity with the morpheme involved in German reduplication. ${ }^{21}$ The first stem has the function of leftmost stems in general: it modifies the meaning of the prefixed unit; in this case it adds a hypocoristic meaning, one signaling "emotional closeness." There appears to be no need here for a separate empty morph, TRUNC, as assumed by Benua (1995) and Itô and Mester (1997). (The morphological structure assumed in these studies is TRUNC $+/$ i//. Féry (1997) simply assumes base $+/ \mathrm{i} /$. .) One point of the present paper is that RED(uplication) and TRUNC(ation) are two instances of the same type of phonologically empty morpheme, and that this morpheme concatenates as any other well-behaved morpheme. It is also worth repeating here that truncations are not necessarily shortenings

stem + prefix + RED (1999:355-356), which is the mirror image of 19. Note that table is not the morphosyntactic head of table-shmable. For Alderete et al., $s h m$ - in English is a prefix attached to RED; in my analysis, $-i$ in German is a suffix attached to RED.

${ }^{21}$ As a reviewer points out correctly, there could be several such empty morphemes, which we could name any way we prefer. The present argument is that German has only one such empty morpheme, used productively in truncation and unproductively in reduplication. 
with respect to the base, compare Hans - Hansi,Kind - Kindi, and all other monosyllabic bases.

Note that 19 is the morphological structure. This structure is well motivated, as it is identical to other word structure proposals made for German and other, similar languages. It accounts for the behavior of truncations with respect to morphological features and the relation to the base word. ${ }^{22}$ We see in the following section that the realization of the truncations diverges from this structure in a significant way. In particular, the head (the right-hand part in 19) is phonologically empty on the surface. In earlier work on reduplication, especially in the fullcopy theory of reduplication of Steriade (1988), there exists a close relationship between truncation and reduplication of a different sort: reduplication in this model consists of a full copy of the base, followed by a truncation process deleting all segments of this copy down to the size of the reduplicant.

The phonological structure differs from the morphological structure. This is by no means uncommon (as witnessed by the frequent mismatch between morpheme boundaries and syllable boundaries); it is just somewhat more extensive and radical in the case under consideration. The phonological suprasegmental structure for Andi, the truncation form of Andreas, is assumed to be the one in 20 .

(20) Phonological structure of truncation

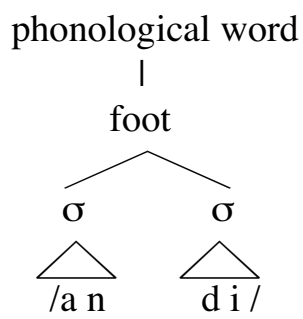

In other words, the claim is that on the surface, the stem containing the reduplicative morpheme is realized, and not the rightmost stem. However, some of the material of the latter stem is still present, by virtue of the fact that RED receives all of its material from this stem. One major

\footnotetext{
22 The suggestion that prosodic word formation is often just "empty" compounding is in fact due to McCarthy and Prince (1990:244): "There is no reduplicative affix at all, and the basic process is the purely morphological one of compounding the base with itself-tautologous compounding."
} 
task of the analysis to be presented now is a motivated proposal for how this can be achieved. In addition, all the empirical generalizations about the phonological shape of the truncations as well as their morphology need to be accounted for.

Based on the three results and claims of this chapter, namely the more prosodic than morphemic status of /i/, the close relationship (and near-complementary distribution) between truncation and reduplication, and the concatenative nature of the morphology in question, I propose in the following yet another analysis of German truncations. This analysis is based on recent ideas formulated in Optimality Theory. Other, alternative analyses of German truncation, formulated within various versions of Optimality Theory, have been discussed above, and are briefly addressed as we move along.

\section{The Optimality of Truncations.}

The discussion of truncations so far has led to the result that they must be described with reference to aspects of three different phonological structures: first, the shape of the truncations themselves, see, for example, their bisyllabicity; second, the underlying form of the base word, see, for example, the voiced obstruent surfacing in the truncations; and third and most questionable, the surface form of the base word, see the commonly made reference to the "first maximal syllable."

From these points it follows that neither a classical, derivational theory of successive rule applications nor a purely surface-oriented theory can do justice to the full facts of German truncations. While the former needs to rely on rule conspiracies in order to derive the surface shapes of truncation words, the latter has, if taken literally and without further modifications, no means of referring to information absent from surface words.

With this motivation, the following draws upon a theory which seems better suited to these needs. The theory is known as Optimality Theory, which has been applied, since it was first formulated by McCarthy and Prince (1993a, 1993b) and Prince and Smolensky (1993), to phonological, morphological, and, to some extent, syntactic and semantic domains of grammatical descriptions.

\subsection{Optimality Theory and Truncation.}

Optimality Theory (OT) views the grammar of natural languages as a system of interacting constraints. Constraints express universal grammatical wellformedness conditions. They are linguistic preferences 
only, insofar as they are routinely violated by linguistic expressions. Violations are always minimal as they can only arise through conflicts between different, conflicting constraints. Languages may differ in the resolution of such conflicts: given two conflicting constraints $\mathrm{A}$ and $\mathrm{B}$, language 1 may be characterized by a constraint ranking $\mathrm{A} \gg \mathrm{B}$ ("adhering to constraint $\mathrm{A}$ is more important than adhering to constraint B"), while language 2 has the reverse constraint ranking, B >> A. Language 1 then allows for a violation of constraint $B$ in order to satisfy constraint $\mathrm{A}$, while language 2 shows the opposite pattern. But note that both $\mathrm{A}$ and $\mathrm{B}$ are present in both languages, and the lower-ranked constraint can be shown to be active if not suppressed by the dominant constraint.

Constraints in general evaluate surface forms, which means that it can be determined for each surface form whether a constraint is violated (and, if needed, how often this is the case). Some constraints, however, evaluate the relation between a lexical entry (input) and a surface form (output); each deviation between input and output counts as a violation of such a constraint. In this sense, Optimality Theory is not purely surface-oriented. ${ }^{23}$

Constraints in OT are interpreted as universal conditions. For this reason, it is not sufficient to postulate a number of arbitrary constraints on the basis of a pattern found in a language. Rather, a constraint must be motivated by demonstrating its presence in a number of diverse languages. This principle contrasts, for example, with the languagespecificity of the design conditions proposed by Neef (1996) above, which only have to be justified in reference to the specific and languageparticular construction under discussion.

One recent variant of OT, CORRESPONDENCE THEORY as developed by McCarthy and Prince (1995), emphasizes not only the relation between the input and output of a linguistic unit, but also the relation between different output forms. Thus, with respect to truncations, we may ask questions such as: How close is the correspondence between the truncation form and its assumed underlying form? How close is the correspondence between the truncation form and other output forms?

${ }^{23}$ For various aspects of German phonology there are at least the studies by Alber (1997, 1998), Féry (1998a, 1998b), Golston and Wiese (1996, 1998), Löhken (1997), Merchant (1996), and the computer implementation by Walther (1996), plus the studies of truncations discussed in the present paper. Wiese (2000:314-318) gives an overview of OT-related work on German phonology. 
This mode of questioning has first been applied to truncation constructions by Benua (1995). She argues that truncations exclusively relate to their base (that is, the full output form), but not to the input. The schema of correspondences, stating the different types of correspondence relations between units (input $\mathrm{I}$, base $\mathrm{B}$, and truncation $\mathrm{T}$ ) postulated by Benua (1995:81), is the one given in 21; see also Itô and Mester 1997.

(21) Correspondence relations for truncations (Benua 1995)

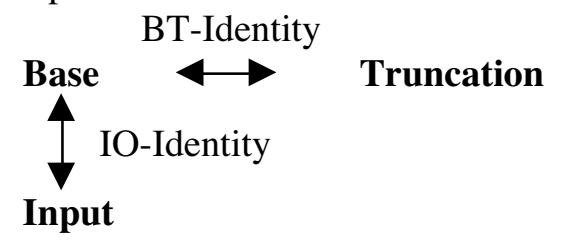

In other words, IT-Identity does not exist as a separate relevant domain of constraint violation. ${ }^{24}$ Note, however, that the data provided in 9 constitute empirical evidence against this claim. The voiced obstruents in the truncations are present only because the inputs have them, not because they are inherently less marked, or because their bases have them. Other very similar problems with Benua's proposal have been pointed out by Sanders (2000). Therefore, a purely output-oriented description of German truncations is not pursued here. Below, constraints demanding input-to-truncation identity are used. However, as the claim is that truncation and reduplication are one and the same phenomenon in disguise, and that there is only one empty morpheme (called RED), I refer to a constraint MAX-IR ("do not delete in truncation/reduplication") below.

On the basis of these cursory remarks on the framework of OT, I propose an analysis of German truncations in the following sections. For the sake of clarity, I present the analysis in two parts: the constraints needed for the basic relationship between base morpheme, affix, and reduplication morpheme are proposed and motivated first (section 5.2); a discussion of the constraints needed for the "pure" phonology of truncations follows in section 5.3. Perhaps needless to say, the analysis

${ }^{24}$ In the original proposal of Correspondence Theory (McCarthy and Prince 1995), the model as in 21 is given as the "Basic Model" for reduplication. In their chapter 6 , they discuss the relevance of faithfulness between input and reduplicants. Benua (1995) postulates a basic difference between reduplication and truncation, in that truncation does not obey faithfulness to the input. 
presupposes the morphological and phonological structures developed in the preceding section; see 19 and 20.

\subsection{Morphophonological Constraints for Truncations.}

The basic problem to be accounted for in this section is how to realize the reduplicative morpheme and the base. Obviously, the realization of the morphological structure is not, for the example used in 19, AndiAndreas. The first relevant group of constraints must therefore disallow the repetition of identical material within some domain. Evidence for the reality of such constraints comes from a number of sources. The shortening within words known as haplology (Stemberger 1981) and illustrated in 22a,b from German and Latin is one instance of such a constraint against repetition, just as the ban against identical adjacent articles in English (22c), and Classical Greek (22d), or the prohibition of identical affixes with the shape /s/ in English (22e). For discussions of these phenomena of identity avoidance within OT, see Golston 1995, Yip 1998, and Plag 1998, among others.

(22) Ban against repetition

a. Haplology in German: Morphonologie < Morpho-phonologie 'morphophonology'

Ruderin $<$ Ruder-er-in 'rower (fem.)'

Zauberin $<$ Zauber-er-in 'sorcerer (fem.)'

b. Haplology in Latin: nutrix < nutri+trix 'feeder (fem.)'

c. English:

*The The Dead video

d. Greek articles: $\quad * \tau \hat{\omega} v \tau \hat{\omega} v,{ }^{*} \tau \hat{\varsigma} \varsigma \tau \hat{\eta} \varsigma$ def. art. gen., pl., sg.

e. English suffixes: *cats's (but: Katz's)

The necessary constraint is formulated here, following proposals made by Yip (1998), as a constraint banning the repetition of material that is identical in adjacent prosodic constituents. Deliberately, the definition is kept very general, bearing in mind that different constituents (syllables, words, morphemes, and others) do not allow repetition of the material contained in them. ${ }^{25}$

${ }^{25}$ On the ban against phonologically identical morphemes by the constraint ANTIHOMOPHONY, see Golston 1995. 
(23) Constraint against repetition $\mathrm{OCP}(\mathrm{X})$

"Two adjacent phonological constituents X, if sister nodes, do not contain identical phonological material."

$\mathrm{X}$ is a variable over any phonological unit, from segments to, say, phonological words. OCP is the OBLIGATORY CONTOUR PRINCIPLE, formulated by McCarthy (1986), Odden (1986), and others, to demand the non-repetition of adjacent identical elements (segments in earlier work). Note that the reduplications found in German (as those in 18) are almost always partial reduplications; they avoid the ban against repetition by partial alternation either in the initial consonant or in the vowel.

The existence of partial (vs. full) reduplication (see 17 and 18 for examples) is also explained by this constraint. Full reduplication maximizes correspondence between input and base, while also maximally violating the constraint against repetition. Any partial reduplication constitutes a compromise between these two tendencies.

While repetition is avoided, it is also true that morphemes should be realized in a one-to-one fashion-each morpheme its own output. Haplology (see 22a) is often avoided because here some subset of an expression serves as the exponent of more than one morpheme, as er in German Zauberin. For this reason, McCarthy and Prince (1995:310) propose the constraint of MORPHEMIC DISJOINTNESS, disallowing the multiple exponence of underlying material:

(24) Ban against multiple exponence

MORPHDIS

"Distinct instances of morphemes have distinct contents, tokenwise."

It is now clear that OCP (X) and MORPHDIs place conflicting demands on a string: while MORPHDIS requires tokens of morphemes to display their own content, the ban against repetition may suppress the former demand exactly when the contents are identical. The present proposal, in a nutshell, is that MORPHDIS loses the battle in German. The fact that haplology exists (22a) provides the evidence that this is correct.

The final / $\mathrm{i}$ / in German truncations is analyzed here as a suffix on the reduplicative morpheme. As a suffix, it needs a base to which it can attach on the right-hand side. (By definition, affixes are contextdependent units of this sort.) It is this demand of the affix that leads to a linearization of stem segments followed by affix segments, and not the 
other way around. The constraint relevant here is assumed to be an alignment constraint of the sort introduced by McCarthy and Prince (1993a), see 25.

(25) Positioning an affix

ALIGN (/i/, L, RED, R)

"The suffix /i/ aligns its left edge with the right edge of its base, the reduplicative morpheme."

As most other affixes, /i/ does not attach to any base, but is restricted, in this case to the empty reduplicative morpheme. Only some of the structures that violate this constraint, such as attaching the suffix to the stem, are considered in the following.

Optimality Theory, reduced to its bare minimum, is a theory of constraint interaction. The burden of work in the computation of grammaticality is done by an evaluation of surface forms with respect to constraint violation in a hierarchy of such constraints. Now that the first group of relevant constraints has been motivated, I demonstrate how these constraints interact in the optimality-theoretic description of the correct truncation forms.

For reasons of conciseness, I first concentrate on the choice of the morphological constituent(s) to be realized in principle. Taking a morphological structure such as 19 as an input, it needs to be determined which of the three constituents is realized at the surface at all. In particular, the ban on the repetition of constituents (23) makes it mandatory to leave out one or more of the morphological items, at the cost of violating the constraints given in 24 and 25. Tableau 26, with the rankings imposed on the set of constraints as determined by the order in the top row of the table, leads to the result that the realization of the reduplicative prefix combination, without a following stem, yields the desired output. $^{26}$

\footnotetext{
${ }^{26}$ In addition to the constraints considered here, there may also be a constraint EXPONENCE requiring that each morpheme is realized somehow. This constraint would make, quite plausibly, the output /i/ worse than it appears in 26 , since the other morphemes remain completely unrealized.
} 
(26) Morphophonological options

\begin{tabular}{||l|c|c|c||}
\hline \hline RED+i+Andreas/ & OCP $(\mathrm{X})$ & ALIGN (/i/, R) & MORPHDIS \\
\hline \hline And+i+Andreas & $*$ & $\sqrt{ }$ & $\sqrt{ }$ \\
\hline $\mathrm{i}+$ Andreas & $\sqrt{ }$ & $*$ & $*$ \\
\hline And+Andreas & $*$ & $*$ & $\sqrt{ }$ \\
\hline $\mathrm{i}$ & $\sqrt{ }$ & $*$ & $\sqrt{ }$ \\
\hline$\leftrightarrow$ And+i & $\sqrt{ }$ & $\sqrt{ }$ & $*$ \\
\hline
\end{tabular}

Whether the phonological content of this prefix combination is Andi, Andri, Anni, etc., is irrelevant in the evaluations of 26; the sequence And used in the table is to be understood as the set of all of these realizations (partial or complete copies of Andreas). The complete realization of the input stem, Andreasi, would also invoke a violation of MORPHDIs, and still be the winner in tableau 26 under the given set and ranking of constraints.

But within the choices made by the evaluation in 26 , there are several further options with respect to the realization of the reduplicated material, such as the forms just mentioned. The following evaluation handles these aspects. Note that the separation between these tableaus is for reasons of exposition (complexity of tableaus) alone. There is no serial derivation involved.

\subsection{Phonological Constraints and their Interaction.}

The second group of constraints needed here is an immediate consequence of the general model sketched in 21 . If a grammar requires identity between input, base, and truncation, then a set of constraints must be considered to implement these requirements. Deviations from perfect identity can be seen from two different perspectives: as deletion of material from the input, or as realization of material that is not part of the input. The former is referred to, in the Correspondence Theory of OT, as violating the constraint family MAX, the latter as violating a constraint family DEP(ENDENCY). Violations of DEP will not be considered here, as they do not seem to play a role (there is no epenthesis); however, violations of MAX are obviously relevant for 
truncations. ${ }^{27}$ If not subject to other constraints (which it most often is), reduplication tends to be complete, as McCarthy and Prince (1994) demonstrate. The same holds for truncations; truncating input material is only justified by obedience to other preferences. This motivates the maximality constraint in 27 , referring to the identity between the input and the truncation form. It has been argued in section 5.1 above that it is the input, and not the surface form of the base, that plays a role here.

(27) Input-truncation identity

MAX-IR

"Underlying segments must be preserved in reduplication."

Final /i/ itself and some parts of the underlying stem are realized in response to the demand of faithfulness to the input. The constraint MAX-IR (27), following McCarthy and Prince 1995, takes care of this. MAX-IR is a ban on deletion in truncation. In accordance with general convention, the deletion of each segment counts as one violation of MAX-IR. (Recall that "R" in MAX-IR refers to the empty morpheme postulated to be part of the relevant morphological structure.)

The next constraint refers to preferred syllable contacts, which have been explored in the literature (cf. Hooper 1976, Murray and Vennemann 1983, Vennemann 1988, and Hargus 1996 within OT) in various versions. A coda consonant should be of higher sonority than the following onset consonant. The formulation in 28 does not admit consonants with equal sonority (such as $/ \mathrm{m} . \mathrm{n} /$ or $/ \mathrm{p} . \mathrm{t} /$ ), but rather bans coda consonants that are of equal sonority as the following onset consonant.

(28) Syllable contact

CODSON

"A coda consonant is more sonorous than the following onset consonant."

The sonority hierarchy referred to in 28 is of course a matter of debate in itself. I assume the one given in 14 above. It differentiates between obstruents, nasals, /1/,/r/, high vowels, and other vowels as segment classes with increasing sonority. The constraint CODSON will then be violated by a syllable contact such as ... 1$]_{\sigma}[\mathrm{r} \ldots$, but will be fulfilled by the mirror image structure $\ldots r]_{\sigma \sigma}[1 \ldots$ As argued at the end of section 3 ,

${ }^{27}$ Féry (1997) and Itô and Mester (1997) use similar, though not identical constraints of the MAX family. 
a series of obstruents or nasals across a syllable boundary (Litt.bi, Gym.ni, etc.) seems to be banned in truncations, providing the crucial evidence for CODSON.

Truncations show a specific prosodic structure, namely one that is almost always bisyllabic (see 8a for exceptions). While there are several alternative ways to achieve this result, I assume here that this is the result of a constraint directly requiring a bisyllabic trochee. A bisyllabic, leftstrong foot seems to be the preferred foot structure in German; see Wiese 1986 and 2000, Féry 1997. A possible way of capturing this strong tendency is the constraint stated in 29.

(29) Preferred prosodic structure

BISYLLTR:

"A phonological word is a bisyllabic trochee."

BISYLLTR is well motivated for German, but is probably more of a blanket constraint, expressing the work of several more elementary constraints. For example, any foot in the word should be trochaic. I do not explore several possible means of decomposing BISYLLTR. Technically, there are alternatives to this constraint anyhow. For example, an alignment constraint requiring that all feet be placed at the left and right edge of their phonological word (Benua 1995) would also ensure that the form is bisyllabic. Alternatively, the bisyllabicity of the form could be the result of a prosodic subcategorization requirement on the suffix /i/.

A further constraint, one widely documented crosslinguistically, is the constraint prohibiting complex onsets of syllables. While German in general allows complex onsets widely, most truncations do not exhibit one, except for those cases in which a morpheme boundary immediately precedes the complex onset, see $8 \mathrm{c}$ above. Constraint 30 takes care of this preference for non-complex onsets; see also Féry 1997:480-482). There is a complication in that it is the internal syllable onset which must be non-complex: numerous truncations start with a consonant cluster, compare Grufti and Studi, and others from the examples presented above. In fact, initial consonants are never deleted, even if the onset is maximally complex as in Sprawi 'student of linguistics', from Sprachwissenschaft 'linguistics'. But internal consonants are deleted, down to the size in which exactly one consonant appears in the onset of the second syllable. (Truncations with vowel hiatus, such as *Zooi 'zoo (hypocor.)', are not attested and seem to be ungrammatical as well. The 
markedness constraints for onsets zoom in on exactly one onset consonant here.)

(30) Ban against complex onsets

*COMPONS (MEDIAL)

"Not more than one segment in the morpheme-internal onset!"

The present claim is that constraints against complex onsets (as well as against dispreferred syllable contacts) are operative in German truncations, following Itô and Mester 1997. The restriction in 30 to internal onsets may seem like a drawback in being parameterized with respect to position, but it reflects the tendency for internal onsets to be simpler than initial onsets. There may be a way of decomposing this onset, for example through constraint interaction of left-alignment and preference for simple onsets, but I do not explore this possibility in the present context.

With the constraints discussed so far, further analysis of German truncations is possible. Let us first consider how the right number of internal consonants is selected from the base Andreas. As shown in 31, a ranking of *COMPONS (MEDIAL) before MAX-IR gives the desired result. MAX-IR still has a role to play, as it prevents the loss of further material, as in *Anni, with an ambisyllabic /n/. Keeping a complete version of the base (Andreasi) violates not only *COMPONS, but also the constraint demanding a bisyllabic trochee, as discussed below.

(31) Consonant drop; *COMPONS >> MAX-IR

\begin{tabular}{|c|c|c|}
\hline /andreas/ & *COMPONS & MAX-IR \\
\hline An.di & $\sqrt{ }$ & $* * * *$ \\
\hline An.ni & $\sqrt{ }$ & $* * * * *$ \\
\hline An.dri & $*$ & $* * *$ \\
\hline An.dre.a.si & $*$ & $\sqrt{ }$ \\
\hline
\end{tabular}

Another class of cases seems to argue against the analysis just proposed. In words containing a postvocalic cluster/st/, these consonants are not truncated, independent of other existing consonants; see 32. 
(32) Internal /st/-cluster

$\begin{array}{lll}\text { Horst } & \text { Horsti } & \text { (proper name) } \\ \text { Geisteswissenschaftler } & \text { Geisti } & \text { 'humanist' } \\ \text { Bastian } & \text { Basti } & \text { (proper name) }\end{array}$

As the /st/-cluster is probably syllable-initial in the first and second types of example (Hor.sti, Gei.sti), these truncation forms seem to display an internal complex onset, violating constraint 30. However, Wiese (1991) has argued that /st/ is in fact a complex segment, analogous to the affricate /ts/. In a way, the immunity of /st/ against truncation provides additional evidence for this claim. The syllabification of Basti and similar examples with a short vowel preceding /st/ is in fact highly debatable.

Another case to be treated here is that of a bad syllable contact in terms of sonority, as in the full form Heinrich. As shown in 33, the constraint CODSON (28) will correctly make Heini the surface truncation output, given that CODSON is ranked higher than MAX-IR. No ranking can or must be imposed upon CODSON and *COMPONS, as these do not conflict.

(33) Cluster with rising sonority; CODSON $>>$ MAX-IR

\begin{tabular}{||l|rll|c||}
\hline \hline Heinrich & CODSON & $*$ COMPONS & MAX-IR \\
\hline \hline 隶Hei.ni & $\sqrt{ }$ & & $\sqrt{ }$ & $* * *$ \\
\hline Hein.ri & $*$ & & $\sqrt{ }$ & $* *$ \\
\hline
\end{tabular}

For Arnold, with the reverse type of heterosyllabic consonant contact, the constraints would correctly choose the truncation form Arni. Next, we consider the case of a truncation form that is perfect, except for being too long. In this case, the constraint BISYLLTR comes into play, again trumping MAX-IR. 
(34) Bisyllabicity; BISYLLTR >> MAX-IR

\begin{tabular}{||l|c|c||}
\hline Heinrich & BISYLLTR & MAX-IR \\
\hline \hline 治Hei.ni & $\sqrt{ }$ & $* * *$ \\
\hline Hein.ri.chi & $*$ & $\sqrt{ }$ \\
\hline
\end{tabular}

A further constraint is needed to ensure that it is generally the leftmost part of the base that is selected for truncation; otherwise, Helmi would be just as good as (or in fact, better than) Willi as the truncation form for Wilhelm. Again, there are several available options in formulating this constraint to ensure this orientation toward the leftmost segments noted in $7 \mathrm{~b}$. It is quite generally true that phonological material is oriented toward the left (and not the right) edge of its respective domain; for example, Golston and Wiese (1998) note that material in German roots shows a strong preference for such an orientation. They postulate alignment constraints requiring consonants and vowels to be aligned with the left edge of the roots. A similar constraint is formulated here in 35, following McCarthy and Prince 1993b and, for German truncations, Féry 1997. It requires the left edge of the truncation to correspond to the left edge of the base.

(35) Left anchoring

ANCHOR-L (RED, L, BASE, L)

"The left edge of the truncation corresponds to the left edge of the base."

The effect of this constraint can be inspected in 36. ANCHOR-L must be ranked above MAX-IR, because the latter constraint by itself would force Helmi as the preferred form (less deletion).

(36) Left-edge orientation; ANCHOR-L >> MAX-IR

\begin{tabular}{||l|c|c|}
\hline \hline /V I lhelm/ & ANCHOR-L & MAX-IR \\
\hline \hline heglimi & $\sqrt{ }$ & $* * * *$ \\
\hline \hline
\end{tabular}

Finally, we need to answer the question why, for a small number of specific forms, complex onsets are found within truncations; see 8c. At present, there is only a tentative answer: for all such forms, it is true that 
there is a prefix-root boundary preceding the culprit, the complex onset. ${ }^{28}$ The claim that there is an internal morpheme boundary in de-pressiv/ De-pri is justified by the recurrence of both parts de- and press-: De-komposition, de-struktiv, de-maskieren, etc., as well as re-press-iv, Kom-press-or, Im-press-ion, etc. In 30, the constraint *COMPONS (MEDIAL) was formulated so that it would apply to morpheme-internal onsets alone. Thus, it would not apply to /pr/ in the evaluation of Depri, see 37. Morpheme boundaries are denoted by [; the exact number of underlying segments in the input is not relevant, because BISYLLTR provides a very early cutoff point in any case.

(37) Why Depri, but not Andri?

\begin{tabular}{|c|c|c|c|}
\hline De[pressiver & BISYLLTR & *COMPONS (MEDIAL) & MAX-IR \\
\hline de[presi & * & $\sqrt{ }$ & $* * * *$ \\
\hline De[pri & $\sqrt{ }$ & $\sqrt{ }$ & $* * * * * *$ \\
\hline De[pi & $\sqrt{ }$ & $\sqrt{ }$ & ******* \\
\hline
\end{tabular}

\section{Final Remarks.}

If the preceding analysis of German truncations is on the right track, the typological classification of German is changed in a subtle way: German is not simply a non-reduplicating language (with a few exceptions). Instead, the relevant structures are present, but overt reduplication is widely suppressed by a constraint. German is thus closer to other (reduplicating) languages than one would think. Furthermore, the inventory of morphological constructions is reduced. Truncations of the sort discussed above are not a category of their own, but can be subsumed under reduplications.

A second general aspect of truncations in German is that they are part of regular, concatenative morphology. Their truncatory properties derive from the fact that there is a phonologically empty morpheme, and from preferences with respect to phonological structure, in particular the

\footnotetext{
${ }^{28}$ Christiane Dombrowski and Barbara Pfisterer (Philipps-Universität Marburg) elicited truncation forms on the basis of prefixed verbs. Students were found to produce forms such as Begrüßi (<be-grüßen 'welcome') or Verschrecki (<verschrecken 'frighten'). These items demonstrate two points: prefixes are often kept in truncations, and clusters following the prefix are never simplified, as predicted by *COMPONS (MEDIAL). The form Depri, which is noted as a lexical exception in $8 \mathrm{c}$, can now receive a different interpretation and be analyzed as morphologically complex.
} 
avoidance of repetition. The marginalization of truncations in German morphology is unwarranted and unnecessary. There is thus no oddity or unnaturalness in the fact that these truncations have become productive in present-day German.

With respect to the more general problem of morphological typology, the hypothesis developed in the present paper is that languages allow either reduplication or truncation in the general case. ${ }^{29}$ Reduplication always involves a violation of constraints against repetition (OCP constraints). Truncation always involves a violation of constraints against faithfulness to the input (constraints of the MAX family). In OT terms, there are two types of languages here, one whose members favor repetition and thus show a ranking of MAX $>$ OCP, and others that favor truncation and thus show the reverse constraint ranking of OCP $>>$ MAX. The fact that German disfavors repetition of identical morphs (see haplology examples in 22) is evidence that German is of this latter type. The more general typology of languages can be stated as follows: for the realization of empty morphemes, the constraints define a scale of possibilities from full reduplication, to partial reduplication, down to truncation, in which more and more constraints dominate the MAX constraints.

In the seemingly marginal part of word formation called i-Bildungen, tendencies come to the surface that have been identified in other work as universal preferences. That marked syllable contacts and complex syllable onsets, for example, are avoided in German is not immediately evident if one looks at underived words alone. Rather, it looks as if this language (along with other Germanic languages) allows complex structures in onsets and codas across the board. But specific corners of the phonology and morphology reveal that "the emergence of the unmarked" (McCarthy and Prince 1994) provides an important principle and insight for these languages just as for any other language: the unmarked, universally preferred structures can be violated in the larger part of the lexicon. Nevertheless, in some of the ecological niches of the phonology and morphology, these structures clearly demonstrate that they are operative and are not simply absent. It is well-known from the

\footnotetext{
${ }^{29}$ The situation is more complicated for languages allowing several types of reduplication. These can be thought of as several morphemes $\mathrm{RED}_{1}, \mathrm{RED}_{2}$, etc., which may be distinct both in meaning and in phonology. One of these could appear as a truncation phenomenon on the surface. (I am grateful here to a reviewer for help in clarifying these issues.)
} 
analysis of phenomena of prosodic morphology such as reduplication that the unmarked structure comes to light under these circumstances. McCarthy and Prince (1994:10-11), for example, demonstrate that reduplication in Nootka involves a reduplicant consisting of an open syllable, while this language admits closed syllables (involving a violation of NOCODA) elsewhere.

The insight that languages do not differ so much in the presence or absence of a grammatical construction, but in its "prominence," is not new. For example, in an explication of Chomsky's view of generative grammar, Pinker (1994:238) writes: "a particular grammatical widget often does a great deal of important work in one language and hums away unobtrusively in the corner of another." The preceding study of German truncation illustrates this by reference to those constraints that disfavor repetition of material, and to those that give preference to unmarked prosodic constituents (syllable constituents, feet). Optimality Theory serves, in contrast to other theories, as a means of giving direct expression to this: all constraints exist in the grammars of all languages, but their prominence differs between languages. The unobtrusive constraints are those that are low-ranked, but not extinct.

\section{REFERENCES}

Alber, Birgit. 1997. Quantity sensitivity as the result of constraint interaction. Phonology in progress - Progress in phonology, ed. by Geert E. Booij and Jeroen van de Weijer, 1-45. (HIL phonology papers, 3.) The Hague: Holland Academic Graphics.

$$
113-141 .
$$

Alderete, John D., Jill N. Beckman, Laura Benua, Amalia E. Gnanadesikan, John J. McCarthy, and Suzanne Urbanczyk. 1999. Reduplication with fixed segmentism. Linguistic Inquiry 30.327-364.

Bartke, Susanne. 1998. Experimentelle Studien zur Flexion und Wortbildung: Pluralmorphologie und lexikalische Komposition im unauffälligen

Spracherwerb und im Dysgrammatismus. (Linguistische Arbeiten, 376.) Tübingen: Max Niemeyer.

Becker, Thomas. 1990. Analogie und morphologische Theorie. Munich:

Wilhelm Fink.

Beckman, Jill N., Laura Walsh Dickey, and Suzanne Urbanczyk. (eds.) 1995. Papers in Optimality Theory. (University of Massachusetts occasional papers in linguistics, 18.) Amherst, MA: Graduate Linguistic Student Association.

Bellmann, Günter. 1980. Zur Variation im Lexikon: Kurzwort und Original. Wirkendes Wort 6.369-383. 
Benua, Laura. 1995. Identity effects in morphological truncation. In Beckman et al., 77-136.

Brockhaus, Wiebke. 1995. Final devoicing in the phonology of German. (Linguistische Arbeiten, 336.) Tübingen: Max Niemeyer.

Bzdega, Andrzej Z. 1965. Reduplizierte Wortbildung im Deutschen. Poznań : Praca wydana z zasilku PAN.

Chomsky, Noam, and Morris Halle. 1968. The sound pattern of English. New York: Harper and Row.

Clahsen, Harald. 1999. Lexical entries and rules of language: A multidisciplinary study of German inflection. Behavioral and Brain Sciences 22.991-1013.

di Sciullo, Anna Maria, and Edwin Williams. 1987. On the definition of word. Cambridge, MA: MIT Press.

Eisenberg, Peter. 1998. Grundriss der deutschen Grammatik. Band 1: Das Wort. Stuttgart and Weimar: J. B. Metzler.

Féry, Caroline. 1997. Uni und Studis: Die besten Wörter des Deutschen. Linguistische Berichte 172.461-489.

- 1998a. On the best optimality-theoretic account of German Final Devoicing. Unpublished manuscript, Universität Tübingen.

- 1998b. German word stress in Optimality Theory. Journal of Comparative Germanic Linguistics 2.101-142.

Fleischer, Wolfgang, and Irmhild Barz. 1995. Wortbildung der deutschen Gegenwartssprache. Tübingen: Max Niemeyer.

Golston, Chris. 1995. Syntax outranks phonology. Phonology 12.343-368.

—, and Richard Wiese. 1996. Zero morphology and constraint interaction: Subtraction and epenthesis in German dialects. Yearbook of Morphology $1995,143-159$.

— Wiese, 165-185.

Greule, Albrecht. 1983. Abi, Krimi, Sponti: Substantive auf - $i$ im heutigen Deutsch. Muttersprache 93.207-217.

Hall, Tracy Alan. 1992a. Syllable-final clusters and schwa epenthesis in German. Silbenphonologie des Deutschen, ed. by Peter Eisenberg, Karl Heinz Ramers, and Heinz Vater, 208-245. Tübingen: Gunter Narr.

- 1992b. Syllable structure and syllable-related processes in German.

(Linguistische Arbeiten, 256.) Tübingen: Max Niemeyer.

Hargus, Sharon. 1996. The first person plural subject prefix in

Babine/Witsuwit'en. Unpublished manuscript, University of Washington, Seattle.

Höhle, Tilman N. 1982. Über Komposition und Derivation: Zur Konstituentenstruktur von Wortbildungsprodukten im Deutschen. Zeitschrift für Sprachwissenschaft 1.76-112.

Hooper, Joan B. 1976. An introduction to Natural Generative Phonology. New York: Academic Press. 
Isačenko, Alexander. 1963. Der phonologische Status des velaren Nasals im Deutschen. Zeitschrift für Phonetik 16.77-84.

Itô, Junko, and Armin Mester. 1997. Sympathy Theory and German truncations. Selected phonology papers from the Hopkins Optimality Workshop/ University of Maryland Mayfest 1997, ed. by Viola Miglio and Bruce Morén, 117-138. College Park, MD: University of Maryland.

- and - forthcoming. On the sources of opacity in OT: Coda processes in German. The syllable in Optimality Theory, ed. by Caroline Féry and Ruben van de Vijver. Cambridge: Cambridge University Press.

Kanngießer, Siegfried. 1985. Strukturen der Wortbildung. Handbuch der Lexikologie, ed. by Christoph Schwarze and Dieter Wunderlich, 134-183. Königstein /Ts: Athenäum.

Kehrein, Wolfgang, and Richard Wiese. (eds.) 1998. Phonology and morphology of the Germanic languages. Tübingen: Max Niemeyer.

Kenstowicz, Michael. 1994. Phonology in generative grammar. Cambridge: Blackwell.

Löhken, Sylvia C. 1997. Deutsche Wortprosodie: Abschwächungs- und Tilgungsvorgänge. (Studien zur deutschen Grammatik, 56.) Tübingen: Stauffenburg.

Marantz, Alec. 1982. Re reduplication. Linguistic Inquiry 13.435-482.

Marcus, Gary F., Ursula Brinkmann, Harald Clahsen, Richard Wiese, and Steven Pinker. 1995. German inflection: The exception that proves the rule. Cognitive Psychology 29.189-256.

McCarthy, John J. 1986. OCP effects: Gemination and antigemination. Linguistic Inquiry 17.207-263.

- 1999. Sympathy and phonological opacity. Phonology 16.331-399.

McCarthy, John J., and Alan S. Prince. 1986. Prosodic Morphology.

Unpublished manuscript, University of Massachusetts, Amherst, and Brandeis University. (Available online at http://ruccs.rutgers.edu/tech_rpt/pm86all.pdf.) — broken plural. Natural Language and Linguistic Theory 8.209-283.

— , and 1993a. Generalized alignment. Yearbook of Morphology 1993, 79-153.

— satisfaction. Unpublished manuscript, Rutgers University Center for Cognitive Science.

—

Prosodic Morphology. Proceedings of the North East Linguistic Society 24, ed. by Merce Gonzalez, 333-379. Amherst, MA.: Graduate Linguistic Student Association.

— , and 1995. Faithfulness and reduplicative identity. In Beckman et al., 249-384. 
Merchant, Jason. 1996. Alignment and fricative assimilation in German. Linguistic Inquiry 27.709-719.

Moravcsik, Edith A. 1978. Reduplicative constructions. Universals of human language, ed. by Joseph H. Greenberg, 297-334. Stanford: Stanford University Press.

Murray, Robert W., and Theo Vennemann. 1983. Sound change and syllable structure in Germanic phonology. Language 59.514-528.

Neef, Martin. 1996. Wortdesign: Eine deklarative Analyse der deutschen Verbflexion. (Studien zur deutschen Grammatik, 52.) Tübingen: Stauffenburg.

Odden, David. 1986. On the role of the Obligatory Contour Principle in phonological theory. Language 62.353-383.

Olsen, Susan. 1986. Wortbildung im Deutschen: Eine Einführung in die Theorie der Wortstruktur. Stuttgart: Alfred Kröner.

Pinker, Steven. 1994. The language instinct. How the mind creates language. New York: William Morrow.

\section{Books.}

Plag, Ingo. 1998. Morphological haplology in a constraint-based morphophonology. In Kehrein and Wiese, 199-215.

Prince, Alan S., and Paul Smolensky. 1993. Optimality Theory: Constraint interaction in generative grammar. Technical Report CU-CS-696-93, Department of Computer Science, University of Colorado at Boulder, and Technical Report TR-2, Rutgers Center for Cognitive Science, Rutgers University.

Raffelsiefen, Renate. 1995. Conditions for stability: The case of schwa in German. Arbeiten des Sonderforschungsbereichs 282, "Theorie des Lexikons”. Düsseldorf: Seminar für Allgemeine Sprachwissenschaft, Heinrich-Heine-Universität.

Sanders, Nathan. 2000. Intra-representational correspondence and truncation. Unpublished manuscript, University of California, Santa Cruz. (Available online at http://ling.ucsc.edu/ sanders/Papers/truncation.pdf.)

Selkirk, Elisabeth O. 1982. The syntax of words. Cambridge, MA: MIT Press.

Stemberger, Joseph Paul. 1981. Morphological haplology. Language 57.791-817.

Steriade, Donca. 1988. Reduplication and syllable transfer in Sanskrit and elsewhere. Phonology 5.73-155.

Vennemann, Theo. 1988. Preference laws for syllable structure and the explanation of sound change. Berlin, New York, and Amsterdam: Mouton de Gruyter.

Walther, Markus. 1995. A strictly lexicalized approach to phonology.

Proceedings der 5. Fachtagung der Sektion Computerlinguistik der DGfS, ed. by James Kilbury and Richard Wiese, 108-113. Düsseldorf: Deutsche Gesellschaft für Sprachwissenschaft, Sektion Computerlinguistik. 
- 1996. OT SIMPLE: A construction-kit approach to Optimality Theory (software). Arbeiten des Sonderforschungsbereichs 282, "Theorie des Lexikons”. Düsseldorf: Seminar für Allgemeine Sprachwissenschaft, Heinrich-Heine-Universität.

. 1999. One-level Prosodic Morphology. Unpublished manuscript, Philipps-Universität Marburg. (Available online at http://pc0880.germanistikkunst.uni-marburg.de/ mal/MAL-TEXTS-archive/1-1199/.)

Werner, Anja. 1996. $i$-Bildungen im Deutschen. Arbeiten des

Sonderforschungsbereichs 282, “Theorie des Lexikons”. Düsseldorf: Seminar für Allgemeine Sprachwissenschaft, Heinrich-Heine-Universität.

Weyerts, Helga, Martina Penke, Ulrike Dorn, Harald Clahsen, and Thomas F.

Münte. 1997. Brain potentials indicate differences between regular and irregular German plurals. Neuroreport 8.957-962.

Wiese, Richard. 1986. Schwa and the structure of words in German. Linguistics 24.697-724.

- 1990. Über die Interaktion von Morphologie und Phonologie:

Reduplikation im Deutschen. Zeitschrift für Phonetik, Sprachwissenschaft und Kommunikationsforschung 43.603-624.

. 1991. Was ist extrasilbisch im Deutschen und warum? Zeitschrift für Sprachwissenschaft 10.112-133.

- 1996. $i$-Bildungen im Deutschen: Prosodische Morphologie und

Repräsentationsebenen in der Phonologie. Unpublished manuscript, HeinrichHeine-Universität Düsseldorf.

Yip, Moira. 1998. Identity avoidance in phonology and morphology.

Morphology and its relation to phonology and syntax, ed. by Stephen G.

Lapointe, Diane K. Brentari, and Patrick M. Farrell, 216-246. Stanford: CSLI

Publications.

Institut für Germanistische Sprachwissenschaft

Philipps-Universität Marburg

35032 Marburg, Germany

[wiese@mailer.uni-marburg.de] 